\title{
BMJ Open Prevalence of diabetes mellitus in outpatients with essential hypertension in China: a cross-sectional study
}

\author{
Jun Liu, Dong Zhao, Jing Liu, Yue Qi, Jiayi Sun, Wei Wang
}

To cite: Liu J, Zhao D, Liu J, et al. Prevalence of diabetes mellitus in outpatients with essential hypertension in China: a cross-sectional study. BMJ Open 2013;3: e003798. doi:10.1136/ bmjopen-2013-003798

- Prepublication history and additional material for this paper is available online. To view these files please visit the journal online (http://dx.doi.org/10.1136/ bmjopen-2013-003798)

Received 13 August 2013 Accepted 15 October 2013

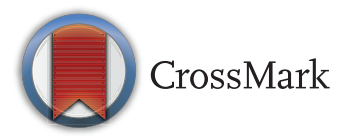

Beijing An Zhen Hospital, Capital Medical University, Beijing Institute of Heart, Lung and Blood Vessel Diseases, Beijing, China

Correspondence to Professor Wei Wang; wangwei_8851@sina.com junliu206@163.com

\section{ABSTRACT}

Objectives: To investigate the prevalence of diabetes mellitus (DM) and new detection of DM using fasting plasma glucose (FPG) and $2 \mathrm{~h}$ plasma glucose (2-hPG) in hypertensive outpatients in China.

Design: Multicenter cross-sectional study.

Setting: 46 hospitals in China.

Participants: Study patients were consecutively recruited from June to December 2009 from hypertension outpatient clinics in 46 hospitals in 22 provinces, autonomous regions and municipalities in China. At least 100 consecutive patients were recruited in each hospital. FPG was measured for all patients and 2-hPG was measured in those without a history of DM. A total of 4942 hypertensive outpatients aged $\geq 20$ years were included

Results: Prevalence of DM was $24.3 \%$ (which included both previously and newly diagnosed cases). Among the 1202 patients with DM, 417 (34.7\%) were newly detected. In patients aged $<45$ years, $52.6 \%$ of cases of DM were newly detected. Of the 417 cases of newly detected diabetes, $54.9 \%$ were identified using FPG tests and the remaining $45.1 \%$ by 2 -hPG tests; $27.1 \%$ of patients with newly detected DM had FPG $<6.1 \mathrm{mmol} / \mathrm{L}$ and $16.5 \%$ had $\mathrm{FPG}<5.6 \mathrm{mmol} / \mathrm{L}$. Among the elderly patients ( $\geq 65$ years), $32.4 \%$ had normal FPG (<6.1 mmol/L) and $24.5 \%$ had optimal FPG $(<5.6 \mathrm{mmol} / \mathrm{L})$.

Conclusions: Our findings showed a high prevalence of DM and newly detected DM among Chinese hypertensive outpatients. Application of additional 2-hPG testing to FPG assay can improve the detection rate of $\mathrm{DM}$, especially in elderly patients.

\section{INTRODUCTION}

The prevalence of hypertension in China has escalated markedly in the past few decades, possibly because of epidemics of unhealthy lifestyle among the Chinese population. According to a recent national survey, the prevalence of hypertension is $18.8 \%$ in the general population, which means there are $>200$ million people with hypertension in China. ${ }^{1}$ Hypertension is often accompanied by diabetes mellitus (DM), and their coexistence

\section{Strengths and limitations of this study}

- Our study had a large sample size and wide geographic coverage.

- Our study sample consisted entirely of hypertensive outpatients enrolled from 46 hospitals (mainly secondary and tertiary hospitals) in 22 cities or provinces in China and may not reflect the status of outpatients from primary hospitals and hypertension among the general population.

- We did not have repeated testing of fasting plasma glucose and $2 \mathrm{~h}$ plasma glucose, which may underestimate or overestimate the prevalence of diabetes mellitus.

can markedly increase the risk of cardiovascular disease (CVD). CVD is at least two times more frequent in hypertensive patients with DM than in those with hypertension alone. ${ }^{2-4}$ Early detection and treatment of DM in hypertensive patients may be particularly important to help reduce the risk of developing cardiovascular complications. ${ }^{5-7}$

DM can be detected by various methods. Among these, the fasting plasma glucose (FPG) assay has been routinely used in China because of its technical convenience and low cost. The China National Diabetes and Metabolic Disorders Study group ${ }^{8}$ reported that $46.6 \%$ of newly detected DM patients had normal FPG and were diagnosed by increased $2 \mathrm{~h}$ plasma glucose (2-hPG) levels in an oral glucose-tolerance test (OGTT). This demonstrates that use of only routine FPG testing may result in a relatively high rate of false-negative diagnosis. The 2010 Chinese Guidelines for the Management of Diabetes recommend ${ }^{9}$ that OGTT (FPG and 2-hPG) should be considered for screening DM in hypertensive patients. However, application of OGTT for screening DM is more time-consuming, laborious and costly compared with an FPG assay. Given the large number $(\sim 200$ million) of hypertensive patients in China, 
nationwide application of additional OGTT to the routine FPG assay for screening DM in all hypertensive patients will carry an economic burden, especially for economically undeveloped regions. Therefore, the FPG assay is still the routine test in most hospitals in China.

Whether adding 2-hPG to the routine FPG test in Chinese hypertensive patients increases the detection rate of DM is still an important research question and lacks evidence from large samples and nationwide studies of hypertension patients. Therefore, the present study investigated the effects of two tests (FPG assay and 2-hPG test) in screening for DM in hypertensive outpatients at 46 hospitals from 22 cities or provinces in China.

\section{METHODS}

\section{Study subjects and design}

This was a cross-sectional national survey of hypertensive outpatients in 46 hospitals across China. We used multistage non-randomised sampling. In the first stage, we recruited 32 tertiary and 14 secondary hospitals from 22 cities or provinces in China. In the second stage, at least 100 consecutive eligible cases, beginning from the same time point, were enrolled from each hospital. The inclusion criteria were (1) patients with definite essential hypertension that had undergone antihypertensive treatment and (2) age $>20$ years. Patients were excluded if they had (1) acute CVD; (2) kidney insufficiency that required dialysis; (3) hospitalisation for any reason; (4) any life-threatening comorbidity or (5) participation in any clinical trial of any drug. A total of 5206 hypertensive patients were enrolled from June 2009 to December 2009. After exclusion of 246 patients with incomplete data for FPG or 2-hPG levels, 4942 patients were included in the final analysis.

\section{Data collection}

A standard questionnaire was used for collecting information on demographic characteristics, smoking status, medical history of DM, hypertension and any other relevant disease. Anthropometric measurements and blood pressure (BP) were obtained by physical examination. The anthropometric indices of height and weight were measured while the patients were barefoot and in light clothing. Body mass index (BMI) was calculated as weight in kilograms divided by height squared in metres. Waist circumference (WC) was measured at a level midway between the lower rib margin and the iliac crest while participants were semiclothed. BP was measured in the right arm in the sitting position with a regular mercury sphygmomanometer after resting for at least 5 min. The mean of three consecutive BP readings was used.

\section{Laboratory tests}

Venous blood samples were collected after overnight fasting for laboratory measurements of serum lipid levels and FPG. After fasting venous blood samples were collected, each participant (except for those with a validated history of DM) received a $75 \mathrm{~g}$ OGTT. OGTT was performed by dissolving $75 \mathrm{~g}$ of glucose in $300 \mathrm{~mL}$ warm water, and then given to patients to drink within $5 \mathrm{~min}$. A venous blood sample was taken $2 \mathrm{~h}$ later for measuring PG level. Total cholesterol (TC), triglyceride (TG) and FPG were determined by the enzymatic method. Low-density lipoprotein cholesterol (LDL-C) and highdensity lipoprotein cholesterol (HDL-C) levels were measured by the homogeneous assay (Daiichi, Tokyo, Japan).

\section{Definitions}

Hypertension was defined according to the 2005 China Guidelines on the Management of Hypertension, ${ }^{10}$ including mean systolic $\mathrm{BP} \geq 140 \mathrm{~mm} \mathrm{Hg}$ and/or mean diastolic $\mathrm{BP} \geq 90 \mathrm{~mm} \mathrm{Hg}$ when no antihypertensive agent was used; or systolic and diastolic BP $<140$ and $<90 \mathrm{~mm} \mathrm{Hg}$, respectively, in patients with a history of hypertension and currently receiving antihypertensive treatment. DM was defined as FPG level $\geq 7.0 \mathrm{mmol} / \mathrm{L}$ or 2-hPG level $\geq 11.1 \mathrm{mmol} / \mathrm{L}$, or with a previous clinical diagnosis. ${ }^{11}$ Obesity was defined as BMI $\geq 28 \mathrm{~kg} / \mathrm{m}^{2}{ }^{2}{ }^{12}$ Central obesity was defined as $\mathrm{WC} \geq 90 \mathrm{~cm}$ in men and $\geq 80 \mathrm{~cm}$ in women. ${ }^{13}$ High triglycerides was defined as TG level $\geq 1.7 \mathrm{mmol} / \mathrm{L}$ based on the criteria of the NCEP Adult Treatment Panel III report. ${ }^{14}$ The educational level was divided into low (primary school), medium-low (junior high school), medium-high (high school) and high (college or university or higher). The medical insurance level was divided into low (reimbursement rate $<30 \%$ ), medium (reimbursement rate $30-79 \%$ ) and high (reimbursement rate $\geq 80 \%$ ).

\section{Sample size estimation}

There are a lack of national data for prevalence of DM among hypertensive patients, thus, we calculated sample size based on prevalence of $9.7 \%$ for DM for the Chinese general population. ${ }^{8}$ The estimated sample size was 3365 if the prevalence of DM were 9.7\%, under assumptions of $\alpha$ (probability of type I error) 0.05 and power $90 \%$. The actual sample size in the study was 4942.

\section{Statistical analysis}

Continuous variables are expressed as the mean (SD) in case of normal distribution, and are otherwise expressed as medians (IQRs). Categorical variables are expressed as number (percentage) and were compared by $\chi^{2}$ test. Linear trend was also calculated. A $\mathrm{p}$ value $<0.05$ was considered statistically significant. Data were managed and analysed using SPSS for Windows V.13.0 (SPSS Inc, Chicago, Iliinois, USA).

\section{RESULTS}

A total of 4942 patients with complete FPG and 2-hPG data entered the final analysis, in which there were 2466 
men $(49.9 \%)$ and 2476 women $(50.1 \%)$, with an average age of $58.5 \pm 10.4$ years. The baseline characteristics of the study patients are summarised in table 1 .

The prevalence of DM in this survey was $24.3 \%$ in hypertensive outpatients (table 2), and 785 (15.9\%) of the hypertensive patients had been previously diagnosed with DM. The prevalence increased with age, from $11.1 \%$ in those aged $<45$ years to $30.7 \%$ in those aged $\geq 65$ years, and this trend was significant $\left(\chi^{2}=80.518\right.$, $\mathrm{p}<0.01)$. Patients with higher TG levels or obesity had a higher prevalence of DM. Of the 1202 patients with DM, $417(34.7 \%)$ were newly diagnosed, and the proportion of newly detected DM was higher in the $<45$ years age

\begin{tabular}{|c|c|}
\hline Characteristics & Total $(n=4942)$ \\
\hline Age, years, mean (SD) & $58.5(10.4)$ \\
\hline $\begin{array}{l}\text { Duration of hypertension, median } \\
\text { (IQR) }\end{array}$ & $6.0(2.3-11.0)$ \\
\hline \multicolumn{2}{|l|}{ Education levels (n, \%) } \\
\hline Low & $791(16.0)$ \\
\hline Medium-low & $1326(26.8)$ \\
\hline Medium-high & $1484(30.0)$ \\
\hline High & $1341(27.1)$ \\
\hline \multicolumn{2}{|l|}{ Medical insurance (n, \%) } \\
\hline Low & 1593 (32.2) \\
\hline Medium & $1916(38.8)$ \\
\hline High & $1433(29.0)$ \\
\hline SBP, mm Hg, mean (SD) & $139.4(17.5)$ \\
\hline $\mathrm{DBP}, \mathrm{mm} \mathrm{Hg}$, mean (SD) & $85.2(11.7)$ \\
\hline $\mathrm{BMI}, \mathrm{kg} / \mathrm{m}^{2}$, mean $(\mathrm{SD})$ & $25.1(3.2)$ \\
\hline WC, $\mathrm{cm}$, mean (SD) & $88.0(10.5)$ \\
\hline Total cholesterol, mmol/L, mean (SD) & $4.91(1.28)$ \\
\hline HDL-C, mmol/L, mean (SD) & $1.23(0.36)$ \\
\hline LDL-C, mmol/L, mean (SD) & $2.83(0.86)$ \\
\hline Triglycerides, mmol/L, median (IQR) & $1.65(1.16-2.32)$ \\
\hline Obesity (n, \%) & $883(17.9)$ \\
\hline Central obesity (n, \%) & 3167 (64.1) \\
\hline High triglycerides (n, \%) & 2374 (48.0) \\
\hline \multicolumn{2}{|l|}{ Main medications ( $\mathrm{n}, \%)$} \\
\hline Diuretic & 417 (8.4) \\
\hline$\beta$-blocker & $1385(28.0)$ \\
\hline Calcium channel blocker & $2835(57.4)$ \\
\hline ACE inhibitor & 1146 (23.2) \\
\hline Angiotensin receptor blocker & $1128(22.8)$ \\
\hline
\end{tabular}

Data are expressed as number (per cent) for categorical variables, as mean (SD) for continuous variables in case of normal distributions and medians (IQRs) otherwise.

The educational level was divided into low (primary school), medium-low (junior high school), medium-high (high school) and high (college or university or higher). The medical insurance level was divided into low (reimbursement rate $<30 \%$ ), medium (reimbursement rate 30-79\%) and high (reimbursement rate $\geq 80 \%$ ). Obesity was defined as a BMl $\geq 28 \mathrm{~kg} / \mathrm{m}^{2}$. Central obesity was defined as $W C \geq 90 \mathrm{~cm}$ in men and $\geq 80 \mathrm{~cm}$ in women. High triglycerides was defined as triglyceride level $\geq 1.7 \mathrm{mmol} / \mathrm{L}$.

BMI, body mass index; DBP, diastolic blood pressure; HDL-C, high-density lipoprotein cholesterol; LDL-C, low-density lipoprotein cholesterol; SBP, systolic blood pressure; WC, waist circumference. group $(52.6 \%)$, and in those with a low educational level $(42.3 \%)$ and low level of medical insurance (43.2\%).

Of the 4157 hypertensive patients without a history of DM, 417 (10\%) were found to have DM. Only 5.5\% (229/4157) were newly diagnosed based on FPG assay, $4.5 \%(188 / 4157)$ were DM patients with increased 2hPG and normal FPG levels (table 3). More patients with diabetes could be identified by OGTT screening from the patients with hypertension aged >65 years without a history of DM compared with younger patients with hypertension, which means that OGTT screening is more efficient for DM among patients with hypertension aged $>65$ years.

Of the 417 patients with newly diagnosed DM, 101 $(24.2 \%)$ had isolated increased FPG levels, $188(45.1 \%)$ had isolated increased 2-hPG levels and $128(30.7 \%)$ had increased FPG and 2-hPG levels (figure 1). In the $\geq 65$ years age group, $73(52.5 \%)$ patients had isolated increased 2-hPG levels, which means the rate of DM detection was underestimated if using only FPG in patients with hypertension with undetected DM.

Among the 417 patients with newly diagnosed DM, $113(27.1 \%)$ had isolated increased 2-hPG levels but $<6.1 \mathrm{mmol} / \mathrm{L}$ FPG levels, $69(16.5 \%)$ had isolated increased 2-hPG levels but $<5.6 \mathrm{mmol} / \mathrm{L}$ FPG levels. In the $\geq 65$ years age group, the prevalence was $32.4 \%$ and $24.5 \%$, respectively (figure 1 ).

\section{DISCUSSION}

This was a cross-sectional nationally representative survey of 4942 outpatients with hypertension from 46 hospitals in 22 provinces across China. The survey identified a high prevalence of DM among outpatients with hypertension $(24.3 \%)$. The prevalence of DM was similar to that reported in other studies. ${ }^{15} 16$ In the present study, the prevalence of previously diagnosed DM was $15.9 \%$ compared with $8.4 \%$ with newly diagnosed DM. The objective of this study was to investigate outpatients with hypertension undergoing treatment; therefore, the detection rate of newly diagnosed DM was lower than that reported in Spanish patients with essential hypertension (11.6\%). ${ }^{16}$ The detection rate of newly diagnosed DM was higher in patients with low educational level, low level of medical insurance, obesity and high triglycerides. Epidemiological studies have shown that patients with DM often cannot be detected in a timely manner, and the prevalence of undiagnosed DM accounted for roughly half of all cases. ${ }^{17}$ Among the 1202 patients with DM in the present study, 34.7\% were newly diagnosed. In the younger age subgroup (<45 years), the proportion $(52.6 \%)$ was high compared with other age groups. These data suggest that the strengthening of DM screening among patients with hypertension is crucial, especially among younger patients or those with poor economic conditions and related metabolic abnormalities (such as obesity or high triglycerides). 
Table 2 Detection rates for diabetes in hypertensive outpatients with different characteristics

\begin{tabular}{|c|c|c|c|c|c|}
\hline & \multirow[b]{2}{*}{ Number } & \multirow[b]{2}{*}{ Prevalence } & \multicolumn{3}{|c|}{ Detection rates of diabetes (\%) } \\
\hline & & & Previous diagnosed & Newly diagnosed & $\begin{array}{l}\text { Proportion of } \\
\text { newly diagnosed }\end{array}$ \\
\hline Total & 4942 & $1202(24.3)$ & 785 (15.9) & $417(8.4)$ & 34.7 \\
\hline \multicolumn{6}{|l|}{ Gender } \\
\hline Male & 2466 & $604(24.5)$ & 409 (16.6) & $195(7.9)$ & 32.3 \\
\hline Female & 2476 & $598(24.2)$ & $376(15.2)$ & $222(9.0)$ & 37.1 \\
\hline \multicolumn{6}{|c|}{ Age group (years) } \\
\hline$<45$ & 512 & $57(11.1)$ & $27(5.3)$ & $30(5.9)$ & 52.6 \\
\hline $45-54$ & 1262 & $275(21.8)$ & $157(12.4)$ & $118(9.4)$ & 42.9 \\
\hline $55-64$ & 1655 & $405(24.5)$ & $275(16.6)$ & $130(7.9)$ & 32.1 \\
\hline$\geq 65$ & 1513 & $465(30.7)^{\star \star} \dagger$ & $326(21.5)^{\star *} \dagger$ & $139(9.2)$ & 29.9 \\
\hline \multicolumn{6}{|l|}{ Education levels } \\
\hline Low & 791 & $222(28.1)$ & $128(16.2)$ & 94 (11.9) & 42.3 \\
\hline Medium-low & 1326 & $336(25.3)$ & $214(16.1)$ & $122(9.2)$ & 36.3 \\
\hline Medium-high & 1484 & $363(24.5)$ & $234(15.8)$ & $129(8.7)$ & 35.5 \\
\hline High & 1341 & $281(21.0)^{\star \star} \dagger$ & 209 (15.6) & $72(5.4)^{\star \star} \dagger$ & 25.6 \\
\hline \multicolumn{6}{|c|}{ Medical insurance } \\
\hline Low & 1593 & 359 (22.5) & $204(12.8)$ & $155(9.7)$ & 43.2 \\
\hline Medium & 1916 & $494(25.8)$ & 331 (17.3) & $163(8.5)$ & 33.0 \\
\hline High & 1433 & $349(24.4)$ & $250(17.4)^{\star \star} \dagger$ & $99(6.9)^{\star} \dagger$ & 28.4 \\
\hline \multicolumn{6}{|l|}{ Obesity } \\
\hline No & 4059 & $941(23.2)$ & $630(15.5)$ & $311(7.7)$ & 33.0 \\
\hline Yes & 883 & $261(29.6)^{\star \star}$ & 155 (17.6) & 106 (12.0) & 40.6 \\
\hline \multicolumn{6}{|l|}{ Central obesity } \\
\hline No & 1775 & 351 (19.8) & 243 (13.7) & $108(6.1)$ & 30.8 \\
\hline Yes & 3167 & $851(26.9)^{\star *}$ & $542(17.1)$ & $309(9.8)$ & 36.3 \\
\hline \multicolumn{6}{|c|}{ High triglycerides } \\
\hline No & 2568 & $570(22.2)$ & $387(15.1)$ & $183(7.1)$ & 32.1 \\
\hline Yes & 2374 & $632(26.6)^{\star \star}$ & $398(16.8)$ & $234(9.9)^{\star *}$ & 37.0 \\
\hline $\begin{array}{l}\text { Data are present } \\
\text { Data were compa } \\
{ }^{*} p<0.05 \text {. } \\
{ }^{* *} p<0.01 \text {. } \\
\text { †Linear trend } p<0\end{array}$ & $\begin{array}{l}\text { number (p } \\
\text { y } \chi^{2} \text { test. }\end{array}$ & & & & \\
\hline
\end{tabular}

In this study, $45.1 \%$ of cases of newly diagnosed DM were detected based on 2-hPG levels. This is consistent with the findings reported by other studies. Yang $e t a l^{8}$ found that $46.6 \%$ of patients with newly diagnosed DM had isolated increased 2-hPG levels in the general Chinese population. Among middle-aged and elderly hypertensive patients, $54.4 \%$ of cases of newly diagnosed DM were detected based on 2-hPG assay. ${ }^{15} \mathrm{Gu}$ et $a l^{18}$ found that $57.6 \%$ of cases of newly diagnosed DM had isolated increased 2-hPG levels among the new-onset hypertensive patients in the Chinese population. For patients with in Spain, $55.3 \%$ of newly diagnosed DM was detected based on 2-hPG assay. ${ }^{16}$ In addition, the present study showed that $52.5 \%$ of newly diagnosed DM detected by 2-hPG was in the elderly subgroup. Previous studies ${ }^{19} 20$ also found that 2-hPG tests were superior to FPG assays in screening for DM in elderly individuals. The Rancho Bernardo Study reported that among individuals aged $>50$ years, $60 \%$ of patients with diabetes were identified by 2-hPG tests. $^{21}$
The present study reported that application of additional 2-hPG to the routine FPG assay can increase detection rate by $4.5 \%$, especially in the elderly group $(6.1 \%)$. At present, there are $\sim 200$ million patients with hypertension in China. According to published data from a national survey (treatment rate of hypertension was $24.7 \%),{ }^{1} \sim 49$ million patients underwent antihypertensive treatment. If using FPG assays alone, $\sim 2$ million patients with DM will be expected to be misdiagnosed. If using OGTT assay, 2-hPG test for DM screening will have an economic burden. This burden may be particularly heavy for some economically underdeveloped regions of China. The 2010 Chinese Guidelines for the Management of Hypertension ${ }^{22}$ recommend that 2-hPG testing should be considered for hypertensive patients with impaired glucose tolerance (FPG $\geq 6.1 \mathrm{mmol} / \mathrm{L}$ ). The present study found that $27.1 \%$ of patients had normal FPG $(<6.1 \mathrm{mmol} / \mathrm{L})$ among the patients with newly diagnosed DM. In 2003, the American Diabetes Association ${ }^{23}$ lowered the inferior threshold of FPG to $5.6 \mathrm{mmol} / \mathrm{L}$ for defining impaired FPG, assuming that 
Table 3 Detection rates for diabetes in hypertensive outpatients according to two methods*

\begin{tabular}{|c|c|c|c|c|}
\hline & Number & $\begin{array}{l}\text { Only } \\
\text { FPG }\end{array}$ & $\begin{array}{l}\text { Only } \\
\text { 2-hPG }\end{array}$ & $\begin{array}{l}\text { FPG } \\
+2-h P G\end{array}$ \\
\hline Total & 4157 & $101(2.4)$ & $188(4.5)$ & $128(3.1)$ \\
\hline \multicolumn{5}{|l|}{ Gender } \\
\hline Male & 2057 & $50(2.4)$ & $86(4.2)$ & $59(2.9)$ \\
\hline Female & 2100 & $51(2.4)$ & $102(4.9)$ & $69(3.3)$ \\
\hline \multicolumn{5}{|c|}{ Age group (years) } \\
\hline$<45$ & 485 & 7 (1.4) & $13(2.7)$ & $10(2.1)$ \\
\hline $45-54$ & 1105 & $29(2.6)$ & $50(4.5)$ & 39 (3.5) \\
\hline $55-64$ & 1380 & $32(2.3)$ & $52(3.8)$ & 46 (3.3) \\
\hline$\geq 65$ & 1187 & $33(2.8)$ & $73(6.1)$ & $33(2.8)$ \\
\hline \multicolumn{5}{|l|}{ Obesity } \\
\hline No & 3429 & $76(2.2)$ & $145(4.2)$ & $90(2.6)$ \\
\hline Yes & 728 & $25(3.4)$ & $43(5.9)$ & $38(5.2)$ \\
\hline \multicolumn{5}{|c|}{ Central obesity } \\
\hline No & 1532 & $25(1.6)$ & $52(3.4)$ & $31(2.0)$ \\
\hline Yes & 2625 & $76(2.9)$ & $136(5.2)$ & $97(3.7)$ \\
\hline \multicolumn{5}{|c|}{ High triglycerides } \\
\hline No & 2181 & $45(2.1)$ & 84 (3.9) & $54(2.5)$ \\
\hline Yes & 1976 & $56(2.8)$ & $104(5.3)$ & $74(3.7)$ \\
\hline
\end{tabular}

individuals with an FPG level above this cut-off value have a markedly higher risk of developing DM, other metabolic abnormalities and complications. However, as shown in our study, when $5.6 \mathrm{mmol} / \mathrm{L}$ was used as a cut-off point, $16.5 \%$ of patients with DM had a normal FPG level $(<5.6 \mathrm{mmol} / \mathrm{L})$. Adam et $a l^{24}$ also observed that $25.8 \%$ of patients with diabetes would have been missed if 2-hPG tests were only performed for patients with abnormal FPG results. These results demonstrate that application of 2-hPG tests may inevitably lead to misdiagnosis of DM if only undertaken in patients with abnormal FPG results. The present study further indicated that $32.4 \%$ (with $\mathrm{FPG} \geq 6.1 \mathrm{mmol} / \mathrm{L}$ as the criterion) and $24.5 \%$ (with FPG $\geq 5.6 \mathrm{mmol} / \mathrm{L}$ as the criterion) of newly diagnosed patients with diabetes would have been misdiagnosed in the older ( $\geq 65$ years) patients. This implies that $2-\mathrm{hPG}$ assay should be performed in elderly patients in order to reduce misdiagnosis, regardless of the abnormal fasting glucose levels.

Potential limitations of this investigation merit consideration. First, our study sample consisted entirely of hypertensive outpatients enrolled from 46 hospitals (mainly secondary and tertiary hospitals) in 22 cities or provinces in China. This factor may limit the ability to generalise our findings, which cannot reflect the status of outpatients from primary hospitals and hypertension in the general population. Second, repeat assays should be conducted every other day for the diagnosis of DM, unless the patients have specific clinical symptoms. 91117 Our study was a large epidemiological investigation, we were not able to collect data for repeat OGTT measurement, which may underestimate or overestimate the prevalence of DM. The American Diabetes Association ${ }^{25}$ and other organisations ${ }^{26}$ recommended using glycated haemoglobin (HbA1c) for DM diagnosis. But in China, the HbA1c test is not widely available, especially in some secondary hospitals.

In conclusion, our findings demonstrate that $25 \%$ of hypertensive outpatients had concomitant DM, and approximately $35 \%$ of DM cases were newly detected. In newly diagnosed DM, $45.0 \%$ of cases were detected based on isolated increased 2-hPG level. Application of additional 2-hPG tests could increase the detection rates of DM by $4.5 \%$ among hypertensive outpatients in China, and especially by $6.1 \%$ in elderly patients.

Acknowledgements The involvement of the study coordinators and their hospitals is acknowledged (see online supplementary appendix).

Contributors $\mathrm{JL}$ contributed to the conception and design, acquisition of data, analysis and interpretation of data, drafted and wrote the paper. DZ contributed to the conception and design, critical revision of this paper for

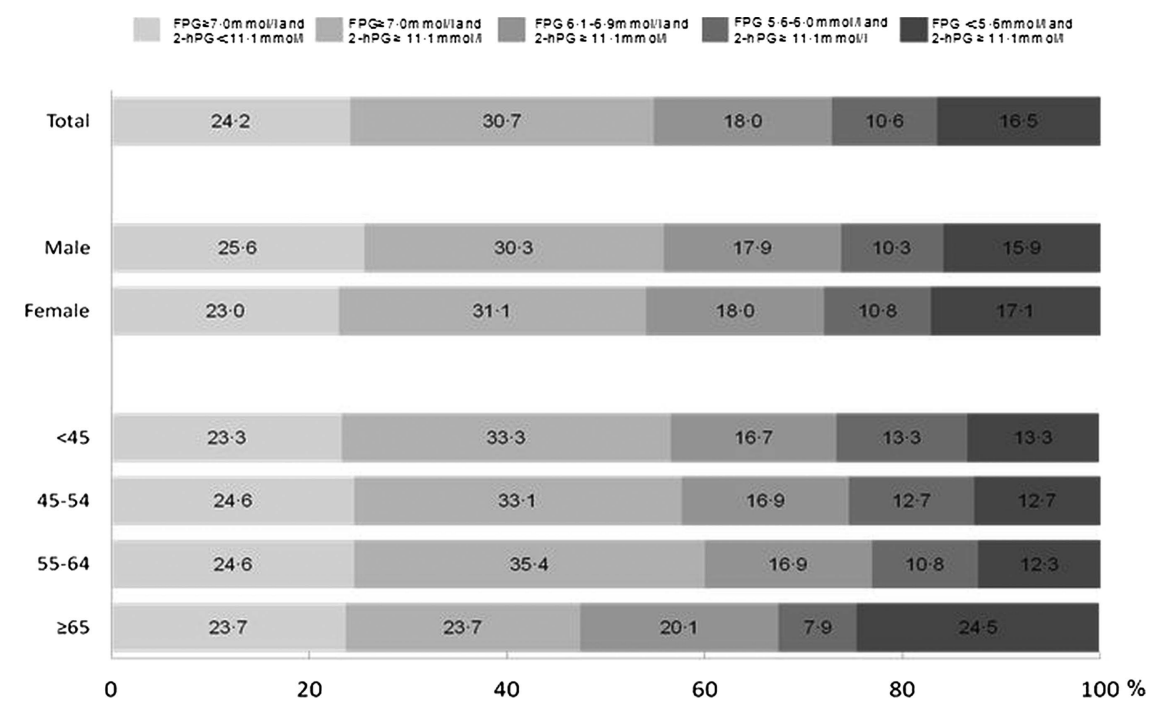

Figure 1 Distribution of the level of fasting plasma glucose and $2 \mathrm{~h}$ plasma glucose in newly detected diabetes. 
important intellectual content, obtaining funding, administrative support and supervision. JL, YQ and JYS contributed to the critical revision of this paper for important intellectual content and technical support. WW contributed to the conception and design, critical revision of this paper for important intellectual content and technical support. All authors read and approved the final manuscript.

Funding This study was funded by an unrestricted grant from the Pfizer Inc. (New York, NY) offices in Beijing, China. The funders had no role in study design, data collection and analysis and decision to publish or preparation of the manuscript.

Competing interests None.

Patient consent Obtained.

Ethics approval The Clinical Research Ethics Committee of Beijing An Zhen Hospital approved this study.

Provenance and peer review Not commissioned; externally peer reviewed.

Data sharing statement No additional data are available.

Open Access This is an Open Access article distributed in accordance with the Creative Commons Attribution Non Commercial (CC BY-NC 3.0) license, which permits others to distribute, remix, adapt, build upon this work noncommercially, and license their derivative works on different terms, provided the original work is properly cited and the use is non-commercial. See: http:// creativecommons.org/licenses/by-nc/3.0/

\section{REFERENCES}

1. Li LM, Rao KQ, Kong LZ, et al. Technical Working Group of China National Nutrition and Health Survey: a description on the Chinese National Nutrition and Health Survey in 2002. Zhonghua Liu Xing Bing Xue Za Zhi 2005;26:478-84.

2. Hirose H, Saito I. Trends in blood pressure control in hypertensive patients with diabetes mellitus in Japan. Hypertens Res 2003;26:717-22.

3. Conen D, Ridker PM, Mora S, et al. Blood pressure and risk of developing type 2 diabetes mellitus: the women's health study. Eur Heart J 2007;28:2937-43.

4. American Diabetes Association. Hypertension management in adults with diabetes. Diabetes Care 2004;27(Suppl):S65-7.

5. Ray KK, Seshasai SR, Wijesuriya S, et al. Effect of intensive contro of glucose on cardiovascular outcomes and death in patients with diabetes mellitus: a meta-analysis of randomized controlled trials. Lancet 2009;373:1765-72.

6. Mohan V, Seedat YK, Pradeepa R. The rising burden of diabetes and hypertension in southeast Asian and African regions: need for effective strategies for prevention and control in primary health care settings. Int J Hypertens. Published Online First: 14 Mar 2013. doi:10.1155/2013.409083

7. Sarwar N, Gao P, Seshasai SR, et al. Diabetes mellitus, fasting blood glucose concentration, and risk of vascular disease: a collaborative meta-analysis of 102 prospective studies. Lancet 2010;375:2215-22.

8. Yang WY, Lu JM, Weng JP, et al. China National Diabetes and Metabolic Disorders Study Group: prevalence of diabetes among men and women in China. N Engl J Med 2010;362:1090-101.

9. China Guideline For Type 2 Diabetes. Beijing: Peking University Medical Press, 2011.
10. National Revision Committee of Chinese guidelines for the Management of Hypertension. Chinese guidelines for the management of hypertension (2005 edition). Beijing: People's Medical Publishing House, 2006.

11. Expert Committee on the Diagnosis and Classification of Diabetes Mellitus. Report of the expert committee on the diagnosis and classification of diabetes mellitus. Diabetes Care 2003;26(Suppl 1): S5-20.

12. Chen C, Lu FC. The guidelines for prevention and control of overweigh and obesity in Chinese adults. Biomed Environ Sci 2004;17(Suppl 1):1-36.

13. Grundy SM, Cleeman JI, Daniels SR, et al. Diagnosis and management of the metabolic syndrome: an American Heart Association/National Heart. Lung and Blood Institute Scientific Statement. Circulation 2005;112:2735-52.

14. Expert Panel on Detection, Evaluation, and Treatment of High Blood Cholesterol in Adults. Executive summary of the third report of The National Cholesterol Education Program (NCEP) expert panel on detection, evaluation, and treatment of high blood cholesterol in adults (Adult Treatment Panel III). JAMA 2001;285:2486-97.

15. Yi YJ, Ran X, Huang XB, et al. An epidemiological study of abnormal glucose metabolism and its risk factors among middle and aged population with hypertension in Chengdu area. Zhonghua Nei Ke Za Zhi 2010;49:301-04

16. García-Puig J, Ruilope LM, Luque M, et al. AVANT Study Group Investigators: glucose metabolism in patients with essential hypertension. Am J Med 2006;119:318-26.

17. Ryden L, Standl E, Bartnik M, et al. Guidelines on diabetes, prediabetes, and cardiovascular diseases: executive summary. The Task Force on Diabetes and Cardiovascular Diseases of the European Society of Cardiology (ESC) and of the European Association for the Study of Diabetes (EASD). Eur Heart $J$ 2007:28:88-136.

18. Gu P, Jiang W, Cheng M, et al. Glucose metabolism in outpatients with new-onset hypertension in Chinese Han population. Clin Exp Hypertens 2012;34:474-81.

19. Choi KM, Lee J, Kim DR, et al. Comparison of ADA and WHO criteria for the diagnosis of diabetes in elderly Koreans. Diabetic Med 2002;19:853-7.

20. Qiao Q, Nakagami T, Tuomilehto J, et al. The DECODA Study Group on behalf of the International Diabetes Epidemiology Group: comparison of the fasting and the 2-h glucose criteria for diabetes in different Asian cohorts. Diabetologia 2000;43:1470-5.

21. Barrett-Connor E, Ferrara A. Isolated postchallenge hyperglycemia and the risk of fatal cardiovascular disease in older women and men. The Rancho Bernardo Study. Diabetes Care 1998; 21:1236-9.

22. Writing Group of 2010 Chinese Guidelines for the Management of Hypertension. 2010 Chinese guidelines for the management of hypertension. Zhonghua Xin Xue Guan Bing Za Zhi 2011;39:579-615.

23. The expert committee on the diagnosis and classification of diabetes mellitus. Follow-up report on the diagnosis of diabetes mellitus. Diabetes Care 2003;26:3160-7.

24. Adam JM, Tarigan NP. Comparison of The World Health Organization (WHO) two-step strategy and OGTT for diabetes mellitus screening. Acta Med Indones 2004;36:3-7.

25. American Diabetes Association. Standards of medical care in diabetes-2010. Diabetes Care 2010;33(Suppl 1):S11-61.

26. NICE. Preventing type 2 diabetes: risk identification and interventions for individuals at high risk. Public Health Guidance PH38. London: National Institute of Health and Care Excellence, 2012. http://www.nice.org.uk/PH38. 